\title{
THE EFFECTS OF EXCLUSION OF THE RIGHT VENTRICLE FROM THE CIRCULATION IN DOGS ${ }^{1}$
}

\author{
By JOHN C. ROSE,2 SALVADOR J. COSIMANO, JR., CHARLES A. HUFNAGEL, AND \\ EDMUND A. MASSULLO \\ (From The Departments of Medicine and Surgery, Georgetown University School of Medicine, \\ and the Cardiovascular Research and Experimental Surgical Laboratories, \\ Georgetown University Hospital, Washington, D. C.)
}

(Submitted for publication June 3, 1955; accepted July 18, 1955)

In experiments bearing on the relationship of "backward failure" of the right ventricle to the elevated venous pressure of clinical heart failure, Starr, Jeffers, and Meade (1) found that extensive cauterization of the right ventricle in dogs was not followed by a significant elevation of venous pressure. Subsequent investigations of the effects of destructive procedures on the right ventricular myocardium have led further to the conclusion that actively functioning right ventricular muscle is not necessary for the maintenance of adequate blood flow through the low pressure pulmonary circulation $(2,3)$.

Rodbard and Wagner (4) created right atriopulmonary artery anastomoses in dogs and occluded right ventricular outflow. Blood was observed to flow directly from the right auricle to the pulmonary artery, and these animals survived up to one hour. Despite these short survivals, and without quantitatively documenting the alterations produced by this acute procedure, these authors concluded that the venous pressure may drive venous return through the lungs without benefit of the right ventricular pump.

If it is possible to by-pass the right ventricle, such observations have clinical as well as basic physiologic importance. However, experiments in progress (5) suggest an active role by the right ventricle in the regulation and maintenance of a normal peripheral venous pressure and adequate pulmonary blood flow. Therefore, it was decided to re-investigate the veno-pulmonary anastomoses briefly studied by Rodbard and Wagner (4).

\footnotetext{
1 Presented (in part) at the National Meeting, American Federation for Clinical Research, Atlantic City, May 1, 1955. Supported (in part) by a U. S. Public Health Service research grant (H-1904).

2 This work was done during the tenure of an Established Investigatorship of the American Heart Association.
}

\section{MATERIALS AND METHODS}

Freeze-dried heterografts of either pig or calf aorta were prepared in the manner described by Hufnagel, Rabil, and Reed (6) and used as veno-pulmonary anastomoses in each of three ways (Figure 1). Group I, consisting of four dogs, had grafts placed between the right auricle and main pulmonary artery. In these animals, attempts were made to occlude the root of the pulmonary artery acutely so that blood gained access to the pulmonary circulation only through the shunt.

Group II, consisting of two dogs, had shunts placed between the superior vena cava and the main pulmonary artery. After freeing the posterior right auricular wall from the adherent right pulmonary veins, a non-crushing clamp was placed across the right auricle in such a manner that the inferior and superior venae cavae were in communication with each other and the shunt, no blood entering the right ventricle (Figure 1).

Group III, thirteen dogs, had shunts placed from both venae cavae to the main pulmonary artery in the manner illustrated (Figure 1). In these dogs, both venae cavae were acutely occluded at their auricular orifices.

Healthy mongrel dogs, weighing 9 to $16 \mathrm{Kg}$. were anesthetized with sodium pentobarbital, $25 \mathrm{mgm}$. per $\mathrm{Kg}$. intravenously, and maintained on positive pressure respirations with 100 per cent oxygen via endotracheal tube. Following the usual surgical preparation, the chest was opened with a generous transverse sternal-splitting incision in the 7th intercostal space.

The pulmonary artery was dissected completely free after partial incision of the pericardium. (When possible, the heart was kept within the pericardium, except in Group I animals when marked right ventricular dilatation was imminent.) The azygos vein was ligated in each procedure.

Partial occlusion for end-to-side anastomoses to the great vessels was accomplished with acutely angled and curved Potts non-crushing clamps. Anastomoses were made with a $5-0$ silk suture on atraumatic needles. The auricular anastomoses in Group I animals was made to the stump of the amputated appendage. In Group III animals, it was found best to place the pulmonary artery and inferior vena cava anastomoses first. The pulmonary artery graft was then anastomosed to the superior vena cava. Finally the inferior vena caval limb of the shunt was connected to the pulmonary artery-superior vena 


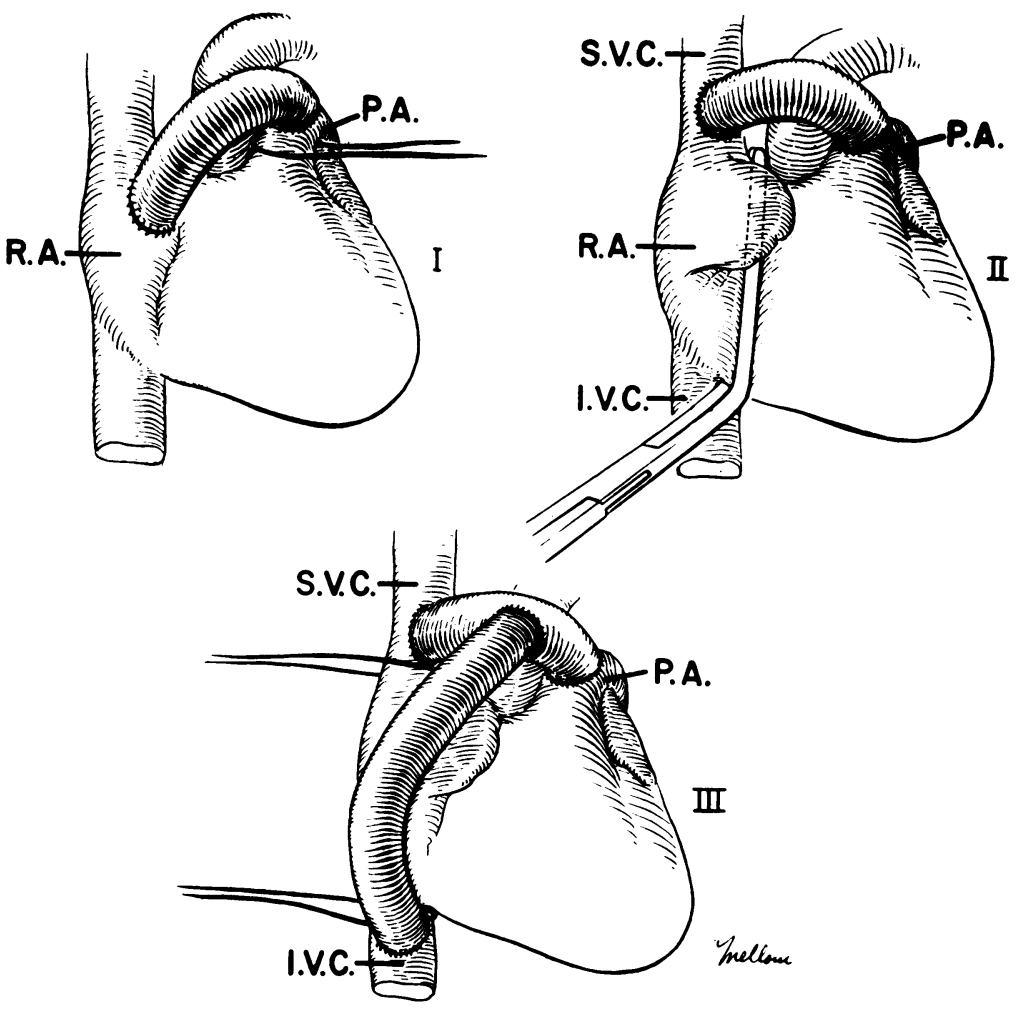

Fig. 1. Diagrams of Three Types of Veno-Pulmonary Shunts

Ligatures and clamp represent points of occlusion of normal pathway of blood in acute experiments. See text for discussion.

cava limb to form a " $T$ " as shown in Figure 1. All grafts were at least as large in internal diameter as the vessels to which they were anastomosed, care being taken to provide wide orifices for unimpeded blood flow.

The operation occasionally lasted up to 3 hours in Group III animals, but frequently only one hour in Group I. Acute studies were performed at the end of this period only in those animals with efficient circulations, as evidenced by the absence of hypotension, slowing of the heart rate or cardiac dilatation.

Intravascular pressures were recorded by strain-gage transducers ${ }^{3}$ and carrier-wave type amplifiers on a direct-writing multiple channel oscillograph. ${ }^{4}$ Pressures were obtained by threading short lengths of $2.5 \mathrm{~mm}$. I.D. polyethylene tubing into the aorta through an iliac artery and into the inferior vena cava through an iliac vein. Pulmonary artery and shunt pressures were obtained in the open chest animals by inserting $1 \mathrm{~mm}$. I.D. polyethylene catheters, or short length of $7 \mathrm{~F}$ ureteral catheters directly into these vessels through purse-string sutures.

Shunt pressures in each group were measured near the pulmonary artery anastomosis. In Figures 3 and 4, prior to the instant designated "Shunt open," the shunts were occluded with non-crushing clamps, and the pres-

${ }^{3}$ Statham Laboratories, Beverly Hills, California.

4 Sanborn Company, Cambridge, Massachusetts. sures recorded were from the segments in direct communication with the pulmonary artery. The zero baseline for shunt pressure tracings was at the level of the right auricle.

All experiments were monitored with continuous electrocardiographic recordings. Flow measurements were attempted using the indicator-dilution curve technique; these generally were unsuccessful because of low and unsteady flow rates during the acute studies.

The material used for infusion in acute studies was a 5 per cent gelatin solution in isotonic sodium chloride (Plazmoid®) ${ }^{5}$ which was warmed to $37^{\circ} \mathrm{C}$. prior to intravenous administration.

Two animals in Group I, one in Group II and one in Group III were permitted to survive for from 2 to 6 weeks with shunts in place but without pulmonary artery, right auricle or venae cavae occlusions. In these animals, angiocardiograms were made, using the Sanchez-Perez Automatic Seriograph. ${ }^{6}$ Roentgenograms were taken at one-half second intervals. Urokon ${ }^{\circledR}$ sodium, 70 per cent, was injected directly into the great veins and right heart through polyethylene catheters.

5 Plazmoid@ was generously supplied by Dr. Joseph P. Webb, Upjohn Company, Kalamazoo, Michigan.

${ }^{6}$ Automatic Seriograph Corporation, College Park, Maryland. 
TABLE I

The effects on intravascular pressures of acute occlusion of right ventricular outflow and inflow in Group I and Group II animals, respectively

(Each value noted is the mean for the number of acute occlusions shown. Occlusion values were taken at or near the time of maximal inferior vena cava pressure rise.)

\begin{tabular}{|c|c|c|c|c|c|c|c|c|c|c|c|c|}
\hline \multirow[b]{3}{*}{ Dog } & \multirow{3}{*}{$\begin{array}{c}\text { Number } \\
\text { of } \\
\text { acute } \\
\text { occlusions }\end{array}$} & \multirow{3}{*}{$\begin{array}{c}\text { Mean } \\
\text { duration } \\
\text { of } \\
\text { occlusion } \\
\text { (seconds) }\end{array}$} & \multicolumn{10}{|c|}{ Pre-occlusion and occlusion values } \\
\hline & & & \multicolumn{2}{|c|}{$\begin{array}{l}\text { Mean aortic } \\
\text { pressure } \\
(m m . H g)\end{array}$} & \multicolumn{2}{|c|}{$\begin{array}{c}\text { Mean P.A. } \\
\text { pressure } \\
(m m . H g)\end{array}$} & \multicolumn{2}{|c|}{$\begin{array}{c}\text { Shunt } \\
\text { pressure } \\
(m m . H g)\end{array}$} & \multicolumn{2}{|c|}{$\begin{array}{c}\text { I.V.C. } \\
\text { pressure } \\
(m m . H g)\end{array}$} & \multicolumn{2}{|c|}{$\begin{array}{c}\text { Heart } \\
\text { rate } \\
\text { (beats } / \text { min.) }\end{array}$} \\
\hline & & & Pre- & Post- & Pre- & Post- & Pre- & Post- & Pre- & Post- & Pre- & Post- \\
\hline $\begin{array}{l}\text { IA } \\
\text { IB } \\
\text { IC } \\
\text { ID }\end{array}$ & $\begin{array}{l}6 \\
3 \\
3 \\
2\end{array}$ & $\begin{array}{l}46 \\
20 \\
49 \\
29\end{array}$ & $\begin{array}{r}77 \\
95 \\
70 \\
112\end{array}$ & $\begin{array}{l}17 \\
21 \\
22 \\
22\end{array}$ & $\begin{array}{l}12 \\
24 \\
7.0\end{array}$ & $\begin{array}{l}6.5 \\
8.0 \\
3.0\end{array}$ & 2.0 & 3.0 & $\begin{array}{r}4.0 \\
9.0 \\
4.0 \\
* 6.0\end{array}$ & $\begin{array}{r}6.5 \\
12.5 \\
7.0 \\
11.0\end{array}$ & $\begin{array}{l}170 \\
170 \\
140 \\
170\end{array}$ & $\begin{array}{l}170 \\
185 \\
140 \\
170\end{array}$ \\
\hline $\begin{array}{l}\text { IIA } \\
\text { IIB }\end{array}$ & $\begin{array}{l}4 \\
3\end{array}$ & $\begin{array}{l}64 \\
72\end{array}$ & $\begin{array}{l}81 \\
78\end{array}$ & $\begin{array}{l}26 \\
15\end{array}$ & & & $\begin{array}{l}2.3 \\
2.0\end{array}$ & $\begin{array}{l}3.6 \\
4.2\end{array}$ & $\begin{array}{l}6.0 \\
6.5\end{array}$ & $\begin{array}{r}9.0 \\
12.0\end{array}$ & $\begin{array}{l}150 \\
110\end{array}$ & $\begin{array}{l}120 \\
110\end{array}$ \\
\hline
\end{tabular}

* Right auricular pressure.

\section{RESULTS}

Angiocardiograms. In preparations of each group studied from 2 to 6 weeks postoperatively with shunts in place but without right ventricular inflow or outflow occlusions, angiocardiograms revealed flow from pulmonary artery to right auricle or venae cavae in accordance with the normal pressure gradient.

\section{Group I: Acute occlusion of right ventricular out- flow}

The hemodynamic alterations following acute occlusion of the pulmonary artery in four Group I animals are summarized in Table I, and a typical example is shown in Figure 2. In each of the fourteen acute experiments, a uniformly reproduci- ble sequence of events occurred. After occlusion, the inferior vena caval pressure rose and the aortic and pulmonary arterial pressure fell precipitously. The right ventricle dilated markedly, and "ventricularization" of the venous pressure pulse appeared indicating marked tricuspid insufficiency. (Tricuspid insufficiency in this experimental situation was also noted by Rodbard and Wagner [4].) The shunt became dilated, filling from the auricular side, although evidently flow from auricle to pulmonary artery was meager. A pressure pulse appeared in the pulmonary artery which was of ventricular origin and transmitted via the regurgitant tricuspid valve, auricle and shunt.

The occlusion was held until it was evident that cardiac contraction had nearly ceased. This varied from 18 to 78 seconds. The occlusion of 78 sec-

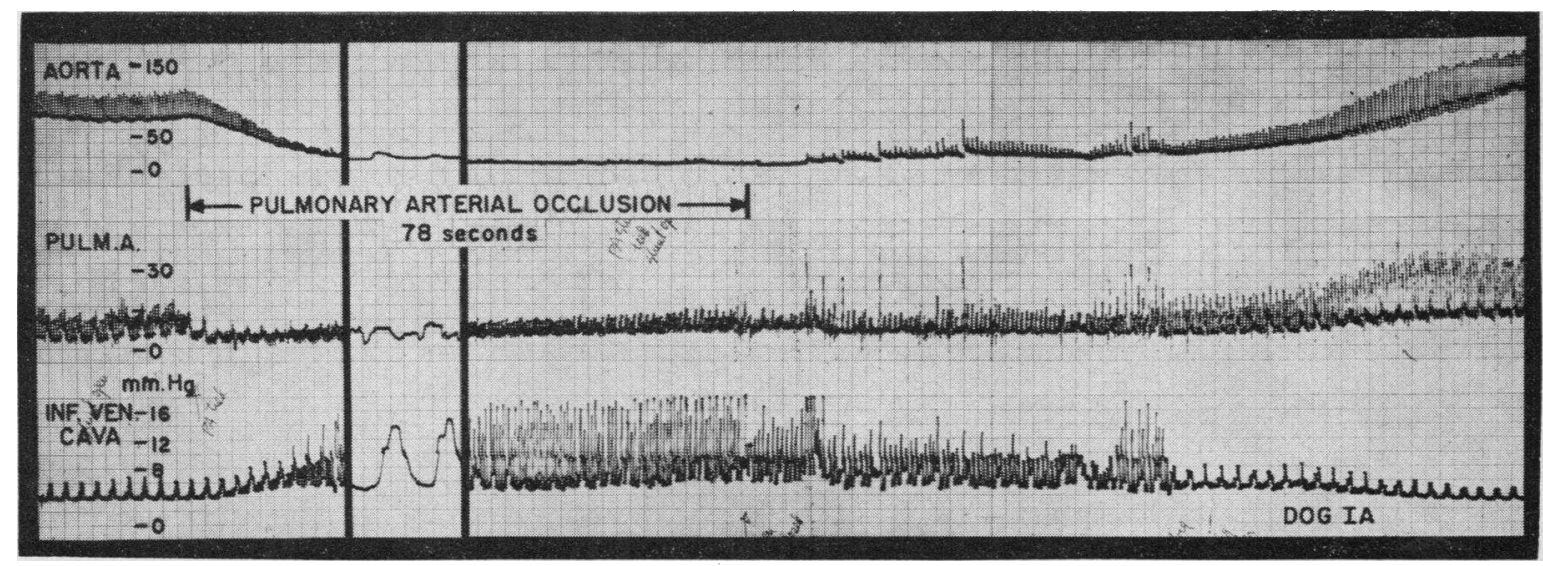

Fig. 2. Cutting Showing Intravascular Pressure Alterations Produced by Pulmonary Arterial Occlusion IN DoG IA

Slow paper speed was $2.5 \mathrm{~mm}$. per sec., fast speed $25 \mathrm{~mm}$. per sec. See text for discussion. 
onds shown in Figure 2 was the longest held in this group and it was evident that aortic blood flow had all but ceased. Prompt recovery usually followed release of the pulmonary artery and no attempts were made to measure the duration of life during pulmonary arterial occlusion.

The enormous dilatation of the right ventricle in this experiment possibly could have caused embarrassment of left ventricular function by displacement of the interventricular septum. Therefore, Shunt II was devised in order to eliminate this factor.

\section{Group II: Acute occlusion of right ventricular inflow}

Data from these seven acute experiments in two dogs are shown in Table I. Since acute dilatation of the right ventricle was eliminated, it was possible to hold right auricular occlusions for longer periods than in the Group I experiments. Figure 3 depicts the most favorable response observed to right auricular occlusion which was held in this instance for 164 seconds. The pressure pulse in the shunt was of auricular origin, probably arising in the unclamped portion of the auricle. After complete recovery in this animal, the right auricular clamp was re-applied. Cardiac function declined gradually with bradycardia and by $64 \mathrm{sec}-$ onds there was a markedly diminished aortic pulsation. This dog lapsed into ventricular fibrillation during chest closure.

It was evident that although right ventricular dilatation was eliminated in this type of shunt, the experiment still did not permit a critical analysis of the factors under study. The operation was technically difficult, requiring careful dissection of the posterior right auricular wall and right pulmonary veins. Despite the lack of conduction abnormalities as indicated by the electrocardiogram, this experiment carried the risk of damaging the sino-atrial conduction apparatus. Finally, it was possible to occlude the coronary sinus unknowingly. Therefore, Shunt III was devised.

\section{Group III: Acute occlusion of both venae cavae at their auricular orifices}

Table II and Figure 4 indicate the responses of Group III animals to venae caval (and azygos vein) occlusion. The response consistently observed was again a marked fall in mean systemic

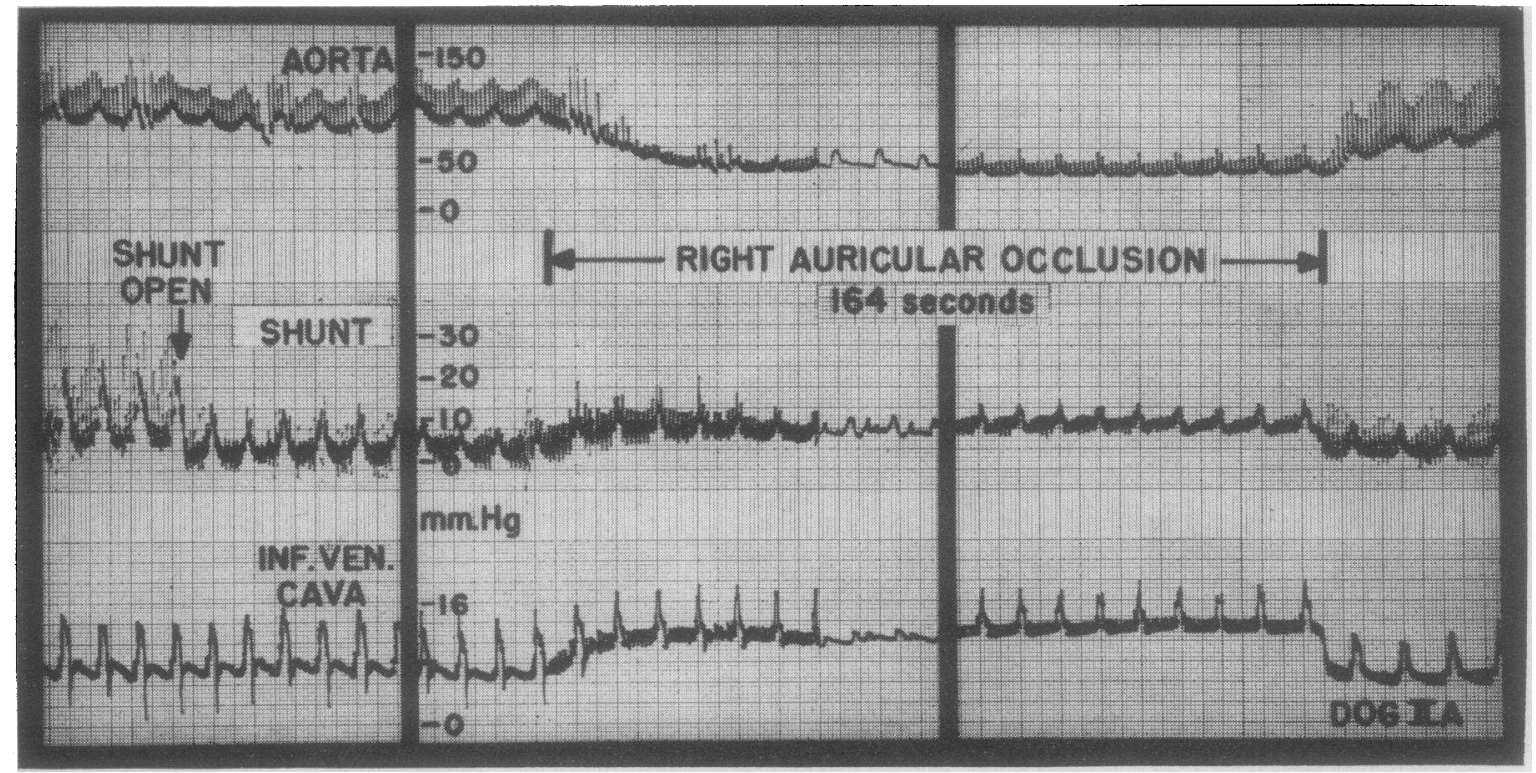

Fig. 3. Cutting Showing Intravascular Pressure Alterations Produced by Right Auricular Occlusion in DoG IIA

Paper speeds the same as in Figure 2. In all Group II and Group III animals, the shunt pressure measured near the pulmonary artery showed a wide pulse pressure prior to opening the shunt. When the shunt was opened, this pulse pressure narrowed as flow towards the vena cava was established. See text for further discussion. 


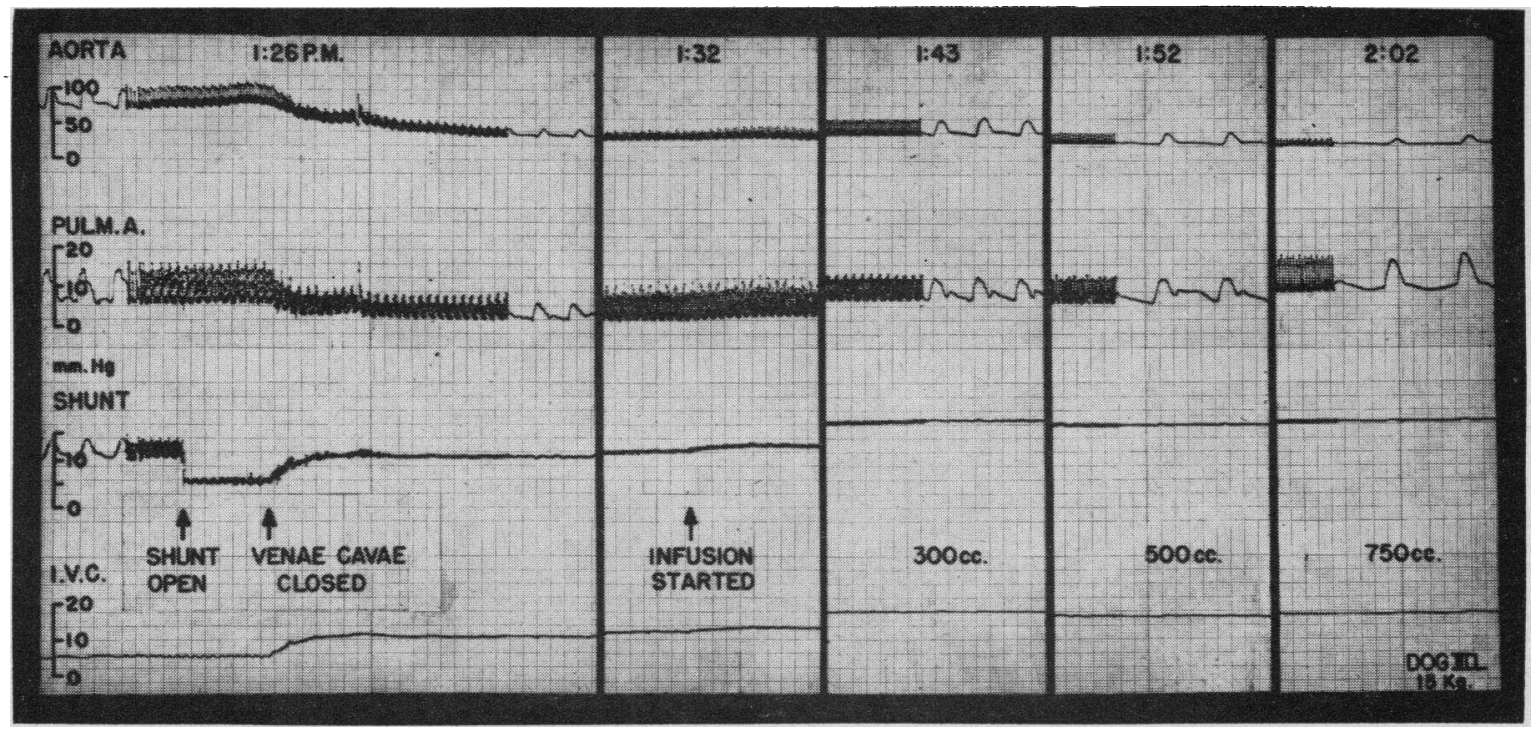

Fig. 4. Cutting Showing Intravascular Pressure Alterations Produced by Venae Caval Occlusion in Dog IIIL AND RESPONSE to IntRavenous Infusion

Slow paper speed $1.0 \mathrm{~mm}$. per sec., fast speed $25 \mathrm{~mm}$. per sec. See text and Table II for explanation.

arterial pressure (to the range of 20 to $36 \mathrm{~mm}$. $\mathrm{Hg}$ ) accompanied by a fall in pulmonary arterial pressure. At the same time, both shunt and inferior vena caval pressures rose, the latter rising to levels between 9 and $22 \mathrm{~mm}$. $\mathrm{Hg}$. The right ventricle did not dilate. The pressure pulse in the pulmonary artery was probably due to ejection of coronary sinus blood through the competent pulmonic valve. Without infusions, these animals exhibited a steady decline in circulatory volume with progressive bradýcardia and hypotension despite markedly elevated central venous pressures. In three animals the total duration of circulatory function was between 6 and 12 minutes at the end of which time the heart had ceased beating.

Survival was prolonged in Group III animals by the infusion of gelatin solution administered intravenously at rates of 20 to $25 \mathrm{cc}$. per minute (Table II, Figure 4). When the infusion began inferior vena caval and shunt pressures rose promptly. Mean aortic pressure rose, the average maximum, elevation being $11 \mathrm{~mm}$. $\mathrm{Hg}$. At the time of maximal response in aortic pressure, central venous pressures ranged from 15 to $30 \mathrm{~mm}$. $\mathrm{Hg}$ representing a mean rise of $9 \mathrm{~mm}$. $\mathrm{Hg}$. Figure 5 shows the means of the pressure alterations occurring in the four infusion experiments and em-

TABLE II

Alterations produced by permanent occlusion of both venae cavae (and azygos vein) in Group III dogs

(Post-occlusion values were taken at the time of maximal rise in inferior vena cava pressure, post-infusion values at time of maximal response in aortic pressure.)

\begin{tabular}{|c|c|c|c|c|c|c|c|c|c|c|c|c|c|c|}
\hline \multirow[b]{4}{*}{ Dog } & \multicolumn{8}{|c|}{ Pre- and post-occlusion values } & \multirow{2}{*}{\multicolumn{4}{|c|}{ Max. response to infusion }} & \multirow{4}{*}{$\begin{array}{l}\text { Total } \\
\text { vol. } \\
\text { infusion } \\
\text { at max. } \\
\text { response } \\
\text { (cc./Kg. } \\
\text { B.W. })\end{array}$} & \multirow{4}{*}{$\begin{array}{c}\text { Duration } \\
\text { circula- } \\
\text { tory } \\
\text { function } \\
\text { (minutes) }\end{array}$} \\
\hline & \multirow{2}{*}{\multicolumn{2}{|c|}{$\begin{array}{c}\text { Mean aortic } \\
\text { pressure } \\
(m m . H g) \\
\end{array}$}} & \multirow{2}{*}{\multicolumn{2}{|c|}{$\begin{array}{c}\text { Mean P.A. } \\
\text { pressure } \\
(m m . H g)\end{array}$}} & \multirow{2}{*}{\multicolumn{2}{|c|}{$\begin{array}{c}\text { Shunt } \\
\text { pressure } \\
(m m . H g) \\
\end{array}$}} & \multirow{2}{*}{\multicolumn{2}{|c|}{$\begin{array}{l}\text { I.V.C. } \\
\text { pressure } \\
(\mathrm{mm} . \mathrm{Hg})\end{array}$}} & & & & & & \\
\hline & & & & & & & & & \multirow{2}{*}{$\begin{array}{c}\text { M.aor. } \\
\text { press. } \\
(\mathrm{mm} . H g)\end{array}$} & \multirow{2}{*}{$\begin{array}{c}\text { M.P.A. } \\
\text { press. } \\
(m m . H g)\end{array}$} & \multirow{2}{*}{$\begin{array}{c}\text { Shunt } \\
\text { press. } \\
(m m . H g)\end{array}$} & \multirow{2}{*}{$\begin{array}{c}\text { I.V.C. } \\
\text { press. } \\
(\mathrm{mm} . H g)\end{array}$} & & \\
\hline & Pre- & Post- & Pre- & Post- & Pre- & Post- & Pre- & Post- & & & & & & \\
\hline IIIA & 68 & 20 & 10.0 & 6.0 & & & 8.0 & 18.0 & & & & & & 12 \\
\hline IIIC & 80 & 32 & 12.0 & 5.0 & & & 7.0 & 13.0 & & & & & & 6 \\
\hline IIIE & 82 & 36 & 14.0 & 12.0 & & & 8.0 & 22.0 & & & & & & 7 \\
\hline III B & 85 & 31 & & & 8.0 & 10.0 & 8.0 & 17.0 & 40 & & 25.0 & 30.0 & 32 & 50 \\
\hline IIIJ & 60 & 20 & 9.0 & 4.0 & & & 7.0 & 14.0 & 30 & 8.0 & & 15.0 & 10 & 13 \\
\hline IIIK & 75 & 30 & 10.0 & 4.0 & 6.0 & 6.5 & 5.0 & 9.0 & 45 & 7.5 & 11.0 & 15.0 & 15 & 50 \\
\hline IIIL & 90 & 32 & 8.0 & 3.0 & 6.0 & 11.0 & 6.0 & 11.5 & 43 & 9.0 & 18.0 & 19.0 & 24 & 39 \\
\hline
\end{tabular}




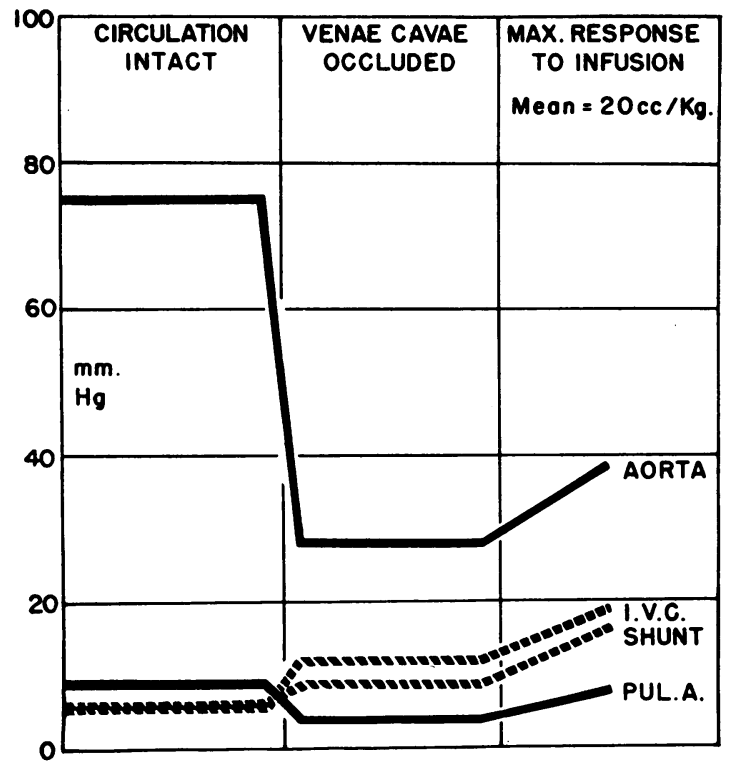

Fig. 5. Chart of Mean Intravascular Pressures in Four Group III Animals in Response to Venae Caval Occlusion and Intravenous Infusion

Note gradient in pressure established from aorta to pulmonary artery.

phasizes the pressure gradient established from aorta to pulmonary artery when the right ventricle was by-passed.

Attempts to rule out reflex depression of aortic pressure following venae caval occlusion were carried out in five additional Group III animals. Two animals were given blocking doses of hexamethonium intravenously prior to occlusion. The course of occlusion was unaltered and systemic pressures were extremely low (18 and $12 \mathrm{~mm}$. $\mathrm{Hg}$ ). These animals survived 5 and 12 minutes, respectively. In the remaining three Group III animals the pulmonary artery was occluded at the same time as the venae caval occlusion. These occlusions were maintained for brief periods up to 30 seconds, during which time the right ventricle was kept full. There were no significant differences noted between occlusion of venae cavae alone and occlusion of venae cavae plus pulmonary artery, except that the small pulse in the pulmonary artery was obliterated by pulmonary artery occlusion. It was concluded that hypotensive reflexes resulting from the lack of normal atrial or ventricular distension were probably of no significance in these experiments.

\section{DISCUSSION}

It appears from the experiments described that the central venous pressure cannot force an adequate blood flow through the lungs in an intact animal without benefit of the right ventricular pump. Despite the low resistance offered by the pulmonary circulation, the loss of pressure from aorta to pulmonary artery (Figure 5) is too great for maintenance of the total circulation without the added energy supplied by right ventricular contraction.

It should be emphasized that the data presented were obtained in acute experiments. Observations were made only of the effects of acute and total occlusion of right ventricular inflow or outflow. The possibility exists that gradual closure of the normal pathway of blood through the right ventricle in these preparations might yield somewhat different results.

Jamison, Gemeinhardt, Alai, and Bailey (7) have given support to the relative "unimportance" of the right ventricle in maintenance of the total circulation with experiments in which a pump was used to replace the left ventricle in dogs. They found that when ventricular fibrillation was induced, circulation through the lungs was maintained. Experiments in progress (5) using a mechanical "left ventricle" of controlled constant output (8), indicate that when "pure" right ventricular failure is produced in this manner, normal blood flows can only be maintained under conditions of hypervolemia and marked venous hypertension of a level not possible to attain in the present experiments using an intact circulation. The present investigation was undertaken because the views of Rodbard and Wagner (4) were incompatible with the observations made with the mechanical "left ventricle."

The observations of Starr, Jeffers, and Meade (1), Bakos (2) and Kagan (9) (using cautery), and Donald and Essex (3) (using right coronary artery ligation) that destruction of the right ventricular wall does not produce significant increments in venous pressure imply that these procedures do not destroy right ventricular function. In fact, a pressure pulse was demonstrated in the pulmonary artery after extensive right ventricular myocardial destruction $(2,3,9)$.

Bakos (2) suggested that the left ventricle transmits its energy to the damaged right ven- 
tricle through muscle bands which circumscribe both ventricles. Kagan (9) suggested that following right ventricular destruction, the pumping action of the right ventricle may be maintained by a subsidiary mechanism such as the contraction of the common interventricular septum. Thus, both of these authors ascribe the pumping action of the right ventricle to a function of the left ventricle. However, Wiggers (10) has recently provided evidence for independent performance of the right ventricle in relation to the left. The present study provides no clue to the source of the energy for contraction of a damaged right ventricle.

Finally, the studies of Landis, Brown, Fauteux, and Wise (11) in experimental right heart failure have demonstrated the importance of an intact right ventricle in the maintenance of normal venous pressure during and following exercise and infusions.

It would appear, then, from the experiments described, and from a review of previous studies, that the right ventricle is an essential pump for the maintenance of normal flows and pressures in the intact circulation. When the right ventricle is acutely excluded from the circulation, the resulting elevated venous pressure is not capable of maintaining adequate lung perfusion.

\section{SUMMARY AND CONCLUSIONS}

Studies of destructive procedures on the right ventricular myocardium have suggested that its active function is not essential for adequate pulmonary blood flow. Experiments are discussed in which veno-pulmonary shunts were used to bypass the right ventricle in dogs. Flow through the shunts was from pulmonary artery to right auricle or venae cavae in accordance with the normal pressure gradient. Acute occlusion of the normal pathway of blood through the right ventricle resulted in marked falls in systemic arterial pressure and elevations of venous pressure. However, even when the venous pressure was elevated with infusions to levels above the normal mean pulmonary arterial pressure, lung perfusion through the shunts remained inadequate.

Thus, the right ventricle is an essential pump for the maintenance of normal pressures and flows in the intact circulation. In these studies, there was no evidence that the total circulation could be maintained when the right ventricle was acutely by-passed. In previous studies, in which attempts were made to destroy the right ventricular myocardium, right ventricular function was not destroyed.

\section{ACKNOWLEDGMENTS}

The authors are grateful for the valuable technical assistance of Dr. Eric Lazaro, Miss Lois Reed, and Messrs. Eugene Rubacky and Thomas Doyle, and for the helpful advice and criticism of Dr. Edward D. Freis. Angiocardiograms were made in the Department of Radiology, Georgetown University Hospital, Dr. Willi Baensch, Director.

\section{REFERENCES}

1. Starr, I., Jeffers, W. A., and Meade, R. H., Jr., The absence of conspicuous increments of venous pressure after severe damage to the right ventricle of the dog, with a discussion of the relation between clinical congestive failure and heart disease. Am. Heart J., 1943, 26, 291.

2. Bakos, A. C. P., The question of the function of the right ventricular myocardium: an experimental study. Circulation, 1950, 1, 724.

3. Donald, D. E., and Essex, H. E., Pressure studies after inactivation of the major portion of the canine right ventricle. Am. J. Physiol., 1954, 176, 155.

4. Rodbard, S., and Wagner, D., By-passing the right ventricle. Proc. Soc. Exper. Biol. \& Med., 1949, 71, 69.

5. Rose, J. C., Freis, E. D., Broida, H. P., Hufnagel, C. A., and Gillespie, J. F., Studies of right ventricular function using a mechanical left ventricle (Abst.). Clin. Research Proc., 1953, 1, 18.

6. Hufnagel, C. A., Rabil, P. J., and Reed, L., A method for the preservation of arterial homo- and heterografts. Surgical Forum, 1953, 4, 162.

7. Jamison, W. L., Gemeinhardt, W., Alai, J., and Bailey, C. P., Artificial maintenance of the systemic circulation without participation of the right ventricle. Circulation Res., 1954, $2,315$.

8. Rose, J. C., Broida, H. P., Hufnagel, C. A., Gillespie, J. F., Rabil, P. J., and Freis, E. D., A method for the study of the circulation using a mechanical left ventricle. J. Applied Physiol., 1955, 7, 580.

9. Kagan, A., Dynamic responses of the right ventricle following extensive damage by cauterization. Circulation, $1952,5,816$.

10. Wiggers, C. J., Evidence for independent action of the right ventricle (abst.). Program (Part II) Second World Congress of Cardiology and 27th Annual Scientific Sessions of the American Heart Association, Washington, D. C., Sept. 12-17, 1954, New York, American Heart Association, 1954, p. 105.

11. Landis, E. M., Brown, E., Fauteux, M., and Wise, C., Central venous pressure in relation to cardiac "competence," blood volume and exercise. J. Clin. Invest., 1946, 25, 237. 